\title{
De João Goulart a Hugo Chávez: A política venezuelana à luz da experiência brasileira*
}

\author{
Octavio Amorim Neto \\ IBRE e EPGE \\ Fundação Getulio Vargas
}

\section{Resumo}

Valendo-se das hipóteses formuladas por Wanderley Guilherme dos Santos para explicar o golpe de 1964 no Brasil, o texto procura identificar as condições que propiciaram a ruptura institucional havida na Venezuela em 1999. A análise de dados relativos à produção legislativa e à distribuição de cadeiras parlamentares e de preferências ideológicas, entre 1959 e 1999, indica que as hipóteses de Santos têm um considerável poder explicativo da crise política que atingiu a Venezuela no final da década de 90 , oferencedo oferecem predições mais precisas a respeito dos motivos da ruptura institucional ter ocorrido em 1999.

Palavras-chave: Democracia, Venezuela, ruptura institucional, regime político

\begin{abstract}
Based on the hypotheses of Wanderley Guilherme dos Santos to explain the Brazilian 1964 coup d'état, this article seeks to identify the leading conditions to the Venezuelan institutional rupture in 1999. Data about the legislative production and the distributions of parliamentary seats and ideological preferences between 1959 and 1999 point that Santos hypotheses have significant explaining capacity of the Venezuelan political crisis at the end of the 90's, specially the causes of the institutional rupture in 1999.
\end{abstract}

Key words: Democracy, Venezuela, institutional rupture, political regime

\footnotetext{
* Este artigo é uma versão modificada de um trabalho preparado para apresentação no Seminário sobre a Venezuela, patrocinado pelo Instituto de Pesquisa de Relações Internacionais do Ministério das Relações Exteriores, realizado no Hotel Le Meridien, Rio de Janeiro, 17-18 de maio de 2001.
} 


\section{Introdução}

Pouco conhecida no Brasil, a Venezuela é, junto com a Colômbia, a mais antiga democracia sul-americana, tendo ingressado no seleto clube dos regimes livres em fevereiro de 1959, quando Rómulo Betancourt assumiu a presidência após disputar a primeira eleição direta realizada no país em 11 anos (a última havia sido em 1947). Em janeiro de 1961, a redemocratização do país foi concluída com a promulgação de uma nova Constituição. Nas duas décadas seguintes, o país assistiria a consolidação daquele que chegou a ser um dos mais institucionalizados sistema partidários da América Latina (Mainwaring \& Scully 1995). Entretanto, no curto espaço de 18 meses, entre a posse de Hugo Chávez, em fevereiro de 1999, e a chamada mega-eleição de julho de 2000, a Constituição de 1961 e o sistema partidário que sob ela vicejou foram irrevogavelmente jogados na lata de lixo da história. Nesse ínterim, foram realizados dois referendos, um, em abril de 1999, para convocar uma assembléia constituinte, outro, em dezembro do mesmo ano, para aprovar a nova Constituição redigida pela assembléia. Depois de tanta agitação política, hoje em dia, democracia, na Venezuela, é um termo em disputa, objeto de vários adjetivos, e um conceito de tortuosa aplicação.

A confusão que hoje paira sobre se a Venezuela ainda é uma democracia decorre, em boa medida, da maneira pela qual se deu o processo de mudança constitucional do país sob a presidência de Hugo Chávez. A convocação do referendo sobre a necessidade de uma assembléia constituinte foi feita por decreto presidencial, um ato que gerou grande controvérsia política e jurídica. Durante os trabalhos da Assembléia Nacional Constituinte (doravante, ANC), o Congresso eleito legitimamente em 1998 foi, para todos os fins práticos, completamente emasculado. Ademais, as constantes ameaças, ultimatos e ofensas que Chávez dirigiu repetidamente às instituições estabelecidas, durante a campanha presidencial de 1998 e após a sua posse em fevereiro de 1999, foram de tal virulência que fizeram analistas nacionais e estrangeiros temer freqüentemente pelo futuro das liberdades civis no país. Para tais analistas, não constituiu surpresa o fato de Chávez ter sido vítima, em abril de 2002, de um grotesco golpe de estado.

Se Chávez estava certo ou não em agir da maneira com que agiu ao longo de 1999, eu não saberia responder. O fato é que, sob sua presidência, produziu-se uma ruptura institucional completa, uma quebra definitiva das regras do jogo político vigentes desde 1958. É isso o que nos interessa entender neste trabalho.

Para tanto, vou me valer - como instrumento heurístico e referência comparativa - da experiência brasileira com a ruptura institucional de um regime democrático, o golpe de 1964, tal qual interpretada por um dos seus mais argutos observadores, Wanderley Guilherme dos Santos, em sua obra premiada Sessenta Quatro: Anatomia da Crise. Creio que tal estratégia de abordagem da política 
venezuelana não é apenas válida do ponto de vista analítico, mas também útil para despertar o interesse e a curiosidade dos cientistas sociais brasileiros, em geral, pouco atentos ao que se passa neste crescentemente importante país vizinho.

O texto está assim estruturado: na próxima seção, trato de mostrar como se consolidou e degenerou a democracia na Venezuela a partir de 1959, com ênfase nos distintos padrões de governança que teve o país até 1998 e na dinâmica do sistema partidário. A terceira seção oferece uma descrição sumária dos eventos cruciais ocorridos em 1999 para mostrar que houve uma ruptura institucional no país. Na quarta, utilizo-me das hipóteses de Wanderley de Guilherme dos Santos (doravante, WGS) para identificar os fatores que levaram à ruptura institucional. Segundo WGS, rupturas institucionais se seguem a crises de paralisia decisória decorrentes de um processo de fragmentação política cum radicalização ideológica. Procurarei verificar, por meio de dados quantitativos, em que medida tal processo ocorreu na Venezuela. Antecipando um pouco os resultados, há, sim, sólidas evidências que mostram ter havido uma crise paralisia decisória na década de 90 . A quinta seção confronta as hipóteses hauridas de WGS com outras explicações relativas à decadência das instituições democráticas na Venezuela. A última seção conclui o texto.

\section{Ascensão e Queda do Sistema de Punto Fijo (1959-1998)}

A relativa longevidade da democracia na Venezuela se deveu, em grande medida, à força dos seus partidos e do sistema partidário (Coppedge 1994; Levine 1973; Kornblith \& Levine 1995) ${ }^{1}$. Os partidos venezuelanos desempenharam um papel fundamental no estabelecimento e consolidação da democracia em função de quatro fatores: (1) a disposição que demonstraram seus líderes em superar diferenças ideológicas para formar pactos de governabilidade (Karl 1991, Navarro 1988); (2) a capacidade que tiveram no esforço de eliminar a atuação de grupos radicais e antidemocráticos durante o auge da guerra fria; (3) sua habilidade em aplacar os militares e submetê-los ao controle civil; (4) sua eficácia na organização, mobilização e representação de diversos grupos sociais ${ }^{2}$.

A força organizacional dos partidos venezuelanos foi fruto, em parte, de sua história pré-democrática e, em parte, de algumas características do sistema eleitoral. Durante a ditadura militar de Pérez Jiménez (1952-1958), o principal de

\footnotetext{
${ }^{1}$ Esta seção se baseia pesadamente em Amorim Neto (1999).

${ }^{2}$ Cumpre notar que a Venezuela é também o maior produtor de petróleo da América Latina e o maior exportador mundial do produto para os Estados Unidos. Os partidos venezuelanos, na tarefa de consolidar a democracia, foram enormemente ajudados pelos vastos recursos financeiros que passou o país a receber a partir da alta do preço do petróleo em 1973. A renda extraída da exportação do petróleo deu às elites governantes os meios necessários para a implementação de políticas redistributivas e compensatórias que em muito serviram para estreitar os laços entre a população de baixa renda e o regime democrático.
} 
partido de oposição ao regime, Acción Democrática (AD), foi legalmente proscrito. Porém, ao mergulhar na clandestinidade, a $A D$ conseguiu sobreviver à brutalidade do regime. Essa verdadeira experiência de guerra acabou por criar uma sólida cadeia de comando vertical dentro do partido. Quando Pérez Jiménez foi finalmente derrubado por uma rebelião civil-militar em janeiro de 1958, as disciplinadas tropas de AD, auxiliadas pelos partidários do Comitê de Organización Electoral Independiente (COPEI) e da Unión Republicana Democrática (URD) não tardaram em ocupar o terreno político e se estabelecer como os principais atores da transição para a democracia. Dado o êxito que teve a AD na queda do antigo regime e na transição para o novo, sua estrutura organizacional passou a ser modelo para as outras agremiações partidárias.

Antes das eleições gerais realizadas ao final de 1958, AD, COPEI e URD assinaram dois acordos históricos: o Pacto de Punto Fijo (pacto do ponto fixo) e o Programa Minimo de Gobierno. O Pacto estipulava que seus signatários se comprometeriam a respeitar o resultado da eleição fosse qual fosse o vencedor, a estabelecer consultas inter-partidárias em questões delicadas e a partilhar cargos e responsabilidade política. O Programa Minimo, por sua vez, lançava as bases de um modelo de desenvolvimento alicerçado no capital estrangeiro e capital privado doméstico, em subsídios para o setor privado e mecanismos de compensação para qualquer reforma agrária. Ou seja, o Programa enunciava os princípios de uma abordagem cautelosa para com a reforma econômica e social (Kornblith e Levine 1995).

Assim, o regime representativo nasceu na Venezuela sob o abrigo de fortes organizações partidárias comprometidas com a moderação política, a partilha do poder e a existência de garantias mútuas, uma fórmula tida como ideal para a estabilização de uma democracia nascente (Lijphart 1976; 1999). À luz da preeminência dos partidos na transição e consolidação democráticas, não deve ser motivo de surpresa o fato de que seus líderes, quando se sentaram para escolher as regras formais do jogo político, tenham optado pela representação proporcional com listas fechadas. Como é sabido, tal sistema, ao dar às lideranças a prerrogativa de determinar a posição dos candidatos nas listas eleitorais, outorga grande poder às instâncias decisórias mais altas dos partidos, dificultando a articulação de interesses locais no seio das bancadas legislativas (Carey \& Shugart 1995; Shugart 1992; Shugart \& Carey 1992). Os membros das últimas, por temerem perder sua vaga na lista do partido nas próximas eleições, se vêem condicionados a uma fiel obediência aos seus líderes. Vale lembrar que, no Brasil, por conta do uso de listas abertas, ocorre algo distinto: como são os eleitores que definem a ordem final dos candidatos nas chapas, os deputados se sentem menos obrigados para com as lideranças partidárias (Mainwaring 1991). Em suma, não é à toa que uma singular combinação de história organizacional e incentivos eleitorais deu vez, na Venezuela, 
a um dos mais disciplinados sistema de partidos do mundo contemporâneo, denominado pelos próprios venezuelanos de partidocracia. A disciplina parlamentar era tão forte na Venezuela que eram raras as votações nominais no Congresso, pois quase não havias dúvidas a respeito de como votaria cada deputado. Por isso, a grande maioria das decisões tomadas em plenário era feita por meio de votação simbólica (Coppedge, 1994).

Como funcionou um sistema político operado por partidos tão fortes, algo distinto da experiência brasileira? Os parágrafos a seguir tratam de oferecer uma breve análise dos principais partidos venezuelanos e de sua ascensão e queda ao longo das últimas quatro décadas.

$A A D$, partido de centro-esquerda com uma base eleitoral multiclassista, foi, de 1958 a 1998, o maior partido do Congresso ${ }^{3}$. As Tabelas 1 e 2 abaixo mostram que a AD alcançou seu auge nas eleições de 1983, quando, além de ganhar a presidência, conquistou 56,5\% das cadeiras da Câmara de Deputados. Seus pontos mais baixos foram em 1999, quando não conseguiu eleger nenhum membro da ANC, e nas últimas eleições gerais, em 2000, quando obteve apenas $18,2 \%$ das cadeiras para deputado. Dos onze presidentes eleitos desde 1947, 6 foram adecos (membros da AD).

Quanto ao COPEI, trata-se de um partido democrata cristão, composto por grupos conservadores, principalmente a Igreja Católica e o empresariado ${ }^{4}$. Do ponto de vista ideológico, se pode dizer que o COPEI é de centro-direita e, tal qual a AD, se vale também de um apelo eleitoral multiclassista. Na primeira eleição do período democrático, o COPEI ficou em terceiro lugar na disputa pelas cadeiras da Câmara de Deputados. Contudo, de 1963 até 1998, manteve-se como a segunda força política do Congresso, tendo vencido também dois pleitos para a presidência da República, em 1968 e 1978. Porém, tal qual a AD, nas três últimas eleições legislativas (1998, 1999 e 2000), o COPEI teve o pior desempenho de sua história, conseguindo parcos $14,4 \%$ das cadeiras da Câmara em 1998, nenhuma na ANC e apenas $4,2 \%$, em 2000 .

\footnotetext{
${ }^{3}$ Sobre a AD, ver Coppedge (1994).

${ }^{4}$ Sobre o COPEI, ver Combellas Lares (1985).
} 


\section{TABELA 1}

\% de Cadeiras por Partido na Câmara dos Deputados da Venezuela (1958-2000)

\begin{tabular}{|c|c|c|c|c|c|c|c|c|c|c|c|}
\hline PARTIDO & 1958 & 1963 & 1968 & 1973 & 1978 & 1983 & 1988 & 1993 & 1998 & 1999 & 2000 \\
\hline$A D$ & 54,9 & 37,1 & 30,8 & 51,0 & 44,2 & 56,5 & 48,3 & 27,6 & 33,0 & & 18,2 \\
\hline COPEI & 14,3 & 21,3 & 27,6 & 32,0 & 42,2 & 30,0 & 33,3 & 27,1 & 14,4 & & 4,2 \\
\hline URD & 25,5 & 16,3 & 7,9 & 2,5 & 1,5 & 1,5 & 1,0 & & & & \\
\hline PCV & 5,3 & & & 1,0 & 0,5 & 1,5 & 0,4 & & & 3,8 & \\
\hline FND (IPFN) & & 12,3 & 1,9 & & & & & & & & \\
\hline FDP & & 9,0 & 5,1 & & & & & & & & \\
\hline MEP & & & 11,7 & 4,0 & 2,0 & 1,5 & 1,0 & & & & \\
\hline $\mathrm{CCN}$ & & & 9,8 & 3,5 & & & & & & & \\
\hline MAS & & & & 4,5 & 5,5 & 5,0 & & 12,6 & 9,6 & 14,5 & 12,1 \\
\hline MAS-MIR & & & & & & & 9,0 & & & & \\
\hline Convergencia & & & & & & & & 12,6 & 1,6 & & 1,2 \\
\hline Causa R & & & & & & & & 20,1 & 2,7 & & 1,8 \\
\hline $\begin{array}{l}\text { Movimiento Va } \\
\text { República }\end{array}$ & & & & & & & & & 24,5 & 67,9 & 47,3 \\
\hline $\begin{array}{l}\text { Proyecto } \\
\text { Venezuela }\end{array}$ & & & & & & & & & 10,6 & & 4,2 \\
\hline Patria Para Todos & & & & & & & & & 3,2 & 6,9 & 0,6 \\
\hline Apertura & & & & & & & & & 0,5 & & \\
\hline Renovación & & & & & & & & & & & \\
\hline Primero Justicia & & & & & & & & & & & 1,8 \\
\hline LAPY & & & & & & & & & & & 1,8 \\
\hline Nuevo Tiempo & & & & & & & & & & & 1,8 \\
\hline Independentes & & & & & & & & & & 4,6 & \\
\hline Outros & & 4,0 & 5,2 & 1,5 & 4,0 & 4,0 & 6,9 & & & & 3,0 \\
\hline $\begin{array}{l}\text { Delegados } \\
\text { Indígenas }\end{array}$ & & & & & & & & & & 2,3 & 1,8 \\
\hline Total (=100\%) & 133 & 178 & 214 & 200 & 199 & 200 & 201 & 199 & 188 & 131 & 165 \\
\hline Fragmentação & 2,6 & 4,3 & 4,9 & 2,7 & 2,6 & 2,4 & 2,8 & 4,5 & 4,7 & 2,0 & 3,6 \\
\hline $\begin{array}{l}\text { Comparecimento } \\
\text { Eleitoral }\end{array}$ & 79,7 & 78,3 & 84,6 & 81,1 & 74,5 & 77,1 & 72,7 & 60,0 & 63,5 & 47,1 & 56,5 \\
\hline
\end{tabular}

Fontes: Coppedge (s/d), Landman (1995) e Venezuela - Consejo Supremo Electoral (1987; 1990). 
TABELA 2

\% de Votos Obtido Pelos Presidentes Venezuelanos (1947-2000)

\begin{tabular}{|l|c|c|c|}
\hline Presidente & Partido & Ano & \% de Votos \\
\hline Rómulo Gallegos & AD & 1947 & 74,4 \\
Rómulo Betancourt & AD & 1958 & 49,2 \\
Raúl Leoni & AD & 1963 & 32,8 \\
Rafael Caldera I & COPEI & 1968 & 29,1 \\
Carlos Andrés Pérez I & AD & 1973 & 48,7 \\
Herrera Campíns & COPEI & 1978 & 46,6 \\
Jaime Lusinchi & AD & 1983 & 58,4 \\
Carlos Andrés Pérez II & AD & 1988 & 52,9 \\
Rafael Caldera II & Convergencia & 1993 & 30,5 \\
Hugo Chávez I & MVR & 1998 & 56,2 \\
Hugo Chávez II & MVR & 2000 & 59,7 \\
\hline
\end{tabular}

Fontes: Coppedge (s/d), Landman (1995), Kornblith e Levine (1995) e Venenzuela - Consejo Supremo Electoral(1987; 1990).

O desenvolvimento do sistema partidário venezuelano ao longo de quatro décadas é fielmente retratado pelo número efetivo de partidos (N), também chamado de índice de fragmentação legislativa, que, ao dar maior peso aos maiores partidos e menor peso aos menores, reflete mais validamente a distribuição de poder legislativo do que uma simples contagem do número de siglas ${ }^{5}$. A primeira eleição, em 1958, produziu um sistema com um número efetivo de partidos menor do que 3, refletindo a maioria absoluta da $A D$ e a distribuição desigual do resto das cadeiras entre COPEI e URD. Na década de 1960, a Câmara dos Deputados tornouse altamente fragmentada, sem nenhum partido a controlar uma maioria parlamentar. Ou seja, nos seus quinze primeiros anos de existência, a democracia venezuelana teve um nítido sistema multipartidário.

Em 1973, AD e COPEI dão um salto, passando juntos a controlar 83,0\% das cadeiras da Câmara, fazendo o sistema partidário retornar ao nível de fragmentação de 1958 ( $N=2,6)$. Outro dado significativo é que nenhum outro partido conseguiu pelo menos $10 \%$ da representação. Na eleição de 1978, esta correlação de forças se manteve, com a dupla AD e COPEI conquistando $86,4 \%$ das cadeiras e verificando-se novamente a ausência de uma terceira força relevante. Conquanto uma franja de pequenas siglas nunca tenha deixado de existir, seja no eleitorado, seja no Congresso, a década de 1970 presenciou a cristalização de uma inequívoca

\footnotetext{
${ }^{5}$ A formula do número efetivo de partidos é $\mathrm{N}=1 / \Sigma x i^{2}$, onde $x i$ é o percentual de cadeiras de cada partido representado na legislatura.
} 
dinâmica bipartidária no seio do regime representativo. Tal dinâmica, não custa ressaltar, tinha como eixo o duopólio de AD e COPEl sobre as cadeiras parlamentares e o revezamento de ambos na presidência. Este situação prevaleceu, com poucas alterações, até 1993.

Aos dois sistemas partidários corresponderam modelos distintos e relativamente estáveis de governança. Assim, no período multipartidário, formaram. se acordos de coalizão para o preenchimento de postos nos gabinetes presidenciais e mesas do Congresso. Já na fase bipartidária, houve quase que apenas gabinetes unipartidários, uma vez que o partido dos chefes de governo contou sempre com uma maioria absoluta ou próxima disto no Congresso ${ }^{6}$.

Em 1993, ano de um novo ciclo eleitoral, a fase bipartidária chega ao fim. Aliás, não seria exagero dizer que as eleições de 1993 constituíram o ponto de inflexão a partir do qual começou a derrocada definitiva do sistema político estabelecido pelo Pacto de Punto Fijo. Elegeu-se pela primeira vez um presidente, Rafael Caldera, não filiado nem à $A D$ nem ao COPEl. Ainda que Caldera não possa ser considerado um outsider do sistema político, uma vez que foi o principal líder do COPEI até o início dos anos 90, tendo também sido nada menos do que presidente da República entre 1969 e 1974, o fato é que ele conduziu expressamente sua campanha eleitoral investindo contra a partidocracia representada por AD e COPEI. Não menos significativo é o fato de que os dois partidos lograram eleger apenas $54,7 \%$ dos deputados. O sistema partidário fragmentou-se sobremaneira $(N=4,7)$, passando a ter cinco partidos com mais de $10 \%$ de cadeiras na Câmara (além de AD e COPEl, também Causa Radical, Movimiento al Socialismo [MAS] e Convergencia). Outra ruptura relevante com o modelo de governança que prevaleceu entre 1973 e 1992 foi a completa ausência de membros de AD e COPEI no gabinete ministerial de Caldera (Amorim Neto 1998:136).

$\mathrm{Na}$ esteira das rupturas políticas ocasionadas pelas eleições de 1993 estão uma série de eventos dramáticos ocorridos nos quatro anos anteriores: o sangrento levante social de 27.28 de fevereiro de 1989 decorrente do aumento do preço das tarifas de transporte público acordado por Carlos Andrés Pérez com o FMI, conhecido como Caracazo; as tentativas de golpe de estado encabeçadas por militares em fevereiro e novembro de 1992, tendo sido a primeira delas liderada pelo então coronel Hugo Chávez; e, finalmente, a destituição do presidente Pérez, em maio de 1993, sob a acusação de malversação de dinheiro público. Como pano de fundo desses tristes espetáculos, uma situação de grande instabilidade econômica, caracterizada por picos inflacionários, quedas bruscas e agudas da taxa de crescimento econômico e o declínio constante do preço do barril de petróleo, motor da economia venezuelana e principal fonte de receita pública. Todos esses

\footnotetext{
${ }^{6}$ Para uma análise detalhada do padrão de formação de governo na Venezuela entre 1959 e 1994, ver Amorim Neto (1998, cap. 5).
} 
fatores contribuíram de forma decisiva para um crescente cinismo da população para com as instituições políticas, as elites dirigentes, em geral, e com os partidos dominantes, em particular. Um indicador eloquente de tal atitude difusa de desconfiança para com a ordem política é a taxa de abstenção eleitoral (ver última linha da Tabela 1). Nas eleições de 1988, o comparecimento foi de $72,7 \%$, enquanto que, nas eleições de 1993, a taxa caiu simplesmente para 60,0\%, estabilizando-se neste patamar em 1998 (63,5\%).

A classe política venezuelana não ficou inerte diante de tantas crises. Várias reformas políticas foram efetuadas entre 1989 e 1995, procurando todas elas reaproximar as instituições democráticas dos eleitores. Foram estabelecidas eleições diretas para governadores de estado e prefeitos em 1989 e instituíram-se distritos uninominais e a regra de maioria para as eleições parlamentares. As mudanças feitas no sistema eleitoral da Câmara merecem atenção especial.

De 1958 até 1988, as candidaturas à Câmara eram apresentadas em listas fechadas distritais, sendo a geografia dos distritos justaposta às dos estados, tal qual no Brasil, devendo os eleitores dar um único voto a uma determinada sigla partidária. Assim como no Brasil, a fórmula eleitoral utilizada para a distribuição de cadeiras era o método d'Hondt. Porém, os partidos sub-representados na alocação de cadeiras ao nível estadual com relação ao seu percentual de votos obtidos nacionalmente tinham direito a receber um número limitado de cadeiras compensatórias. Para um partido credenciar-se a receber cadeiras compensatórias, tinha que haver recebido um número de votos pelo menos igual ao total de votos dados nacionalmente dividido pelo número de cadeiras em disputa em todos os estados. Recapitulando: as duas principais diferenças entre o sistema eleitoral venezuelano do período 1958-1988 e aquele vigente, hoje, no Brasil é a utilização de listas fechadas e de cadeiras compensatórias na Venezuela. A partir das eleições de 1993, o sistema eleitoral venezuelano tornou-se muito mais complexo e distinto do brasileiro e bem semelhante ao alemão, seu modelo inspirador. Estabeleceu-se que metade das cadeiras fixas (por oposição às compensatórias) seria disputada em distritos uninominais e pela regra de maioria simples. A outra metade seria disputada pelo sistema antigo, isto é, por meio de listas fechadas apresentadas em cada estado e com a distribuição de cadeiras regida pela fórmula D'Hondt. O eleitor passou a ter dois votos: um para as cadeiras uninominais e outro para as listas plurinominais. Por fim, manteve-se a sistemática de alocação de cadeiras compensatórias.

O objetivo primordial da reforma eleitoral era suavizar o controle férreo exercido pelas lideranças partidárias sobre a representação política, permitindo, assim, uma maior articulação de interesses locais e, consequentemente, uma maior aproximação entre representantes e representados. Esperava-se que o estabelecimento de distritos uninominais teria um papel fundamental na 
consecução de tais objetivos porque, sendo eles bem menores que os tradicionais distritos plurinominais (os estados), facilitariam a comunicação entre eleitores e candidatos e o controle destes por aqueles. Os resultados frustraram as intenções dos advogados das reformas. Como já mencionado, a abstenção nas eleições para a Câmara aumentou enormemente de 1988 a 1998. As eleições diretas para os governos subnacionais também não reanimaram o eleitorado. Muito pelo contrário. Nas primeiras eleições para governadorias e prefeituras, em 1989, a abstenção foi de 55,0\%; nas eleições seguintes, em 1992, a abstenção foi de 50,8\%; e, nas de 1995, 53,8\% (Kornblith, 1996). Ademais, estudos empíricos mostraram que o comportamento legislativo dos deputados em pouco mudou depois da implementação das reformais eleitorais, máxime no que concerne à disciplina parlamentar (Crisp, 1998b; Kulisheck,1997).

Duas razões podem explicar a ineficácia das reformas. Em primeiro lugar, o fato de terem tido pouco tempo de vigência. Ou seja, não é de uma hora para outra que se mudariam velhas práticas políticas. Segundo, a sólida estrutura organizacional dos grandes partidos, um dos pilares da partidocracia, permaneceu intocada. Quer isto dizer que os líderes partidários continuaram a possuir recursos políticos suficientes para sobrestar os incentivos gerados pelas novas regras eleitorais e, portanto, para continuar a fazer valer o seu peso no processo decisório.

A ineficácia das reformas combinada com o fracasso econômico do segundo governo de Caldera ( 3 anos de recessão em 5 anos de mandato), entretanto, tendeu a realimentar as condições que as motivaram. Prova disto é que, nas eleições realizadas em dezembro de 1998, todas as tendências que se manifestaram em 1993 se aguçaram. Foi eleito para a presidência um militar, Hugo Chávez, que, durante toda a campanha, atacou violentamente não apenas os partidos dominantes como toda a ordem política vigente, prometendo nada menos que a convocação de uma assembléia constituinte com poder para dissolver o Congresso. Ou seja, um outsider por excelência. Some-se a isto o fato de que a AD e COPEI chegaram ao fundo do poço em termos de cadeiras na Câmara de Deputados: $42,6 \%$. Registre-se que, pela primeira vez na história da Venezuela democrática, as duas esfinges do regime passaram a controlar menos de $50 \%$ das cadeiras da Câmara. Com o declínio sem precedente de AD e COPEI e a presença de outros três partidos com mais de $10 \%$ de cadeiras na Câmara (desta vez, eles foram o MAS, o Projeto Venezuela e o Movimento $V^{a}$ República), o sistema partidário nunca se encontrou tão fragmentado como desde 1968. Por último, como era de se esperar depois de uma campanha eleitoral tão rancorosa, o novo presidente, apesar de seus partidários estarem em minoria na Câmara (tinham 37.2\% das cadeiras), decidiu obviamente não formar qualquer tipo de coalizão com AD ou COPEI, mas, isto sim, optou por uma estratégia de aniquilação dos dois partidos e do sistema constitucional sob o qual vicejaram. 
Em suma, os quatro fatores citados no começo da seção como responsáveis pela longevidade da democracia na Venezuela não estavam mais atuando na política do país na segunda metade década de 1990. Em primeiro lugar, a disposição para estabelecer pactos de governabilidade perdeu-se completamente em vista do altíssimo grau de confrontação existente entre os partidos tradicionais e seus opositores. Segundo, com o fim da guerra fria, as elites políticas perderam um inimigo comum que poderia forçá-las a cooperar entre si, qual seja, os partidos de extrema esquerda. Cabe lembrar que esse "cimento cooperativo" já estava fora de uso há muito tempo. Terceiro, a capacidade das elites civis de controlar os militares chegou ao seu nível mínimo com as duas tentativas de golpe de 1992 e a ascensão do coronel Chávez à presidência. Quarto, com as crescentes taxas de alienação eleitoral, ficou claro que a capacidade que tinham os partidos tradicionais de incorporar, organizar, mobilizar e representar os mais diversos grupos sociais encontrava-se seriamente comprometida.

\section{A Ruptura Institucional de 1999}

No dia 2 de fevereiro de 1999, Hugo Chávez assumiu a presidência ainda sob as regras da Constituição de 1961. No dia 20 de dezembro do mesmo ano, promulgou-se uma nova Constituição. Essa mudança profunda no ordenamento constitucional da Venezuela não se fez da mesma maneira que em outros países latino-americanos ao longo das décadas de 1980 e 1990, tal qual no Brasil em 1988, na Colômbia em 1991 e na Argentina em 1994. Estes três processos de transformação constitucional ocorreram sob as regras vigentes do jogo político, sem que estas jamais tenham sido violadas. Foram, em suma, processos de mudança pactuada entre as principais forças políticas do país. Quando a mudança constitucional se faz à margem das regras do jogo, isto é, de forma ilegal, temos o que se pode chamar de ruptura institucional. O conceito de ruptura institucional é uma generalização daquilo que WGS chamou, para o caso específico do Brasil em 1964, de violência política, isto é “... quaisquer mudanças ilegais nas regras do jogo ..." (Santos 1986:32). Rupturas institucionais abarcam tanto golpes de estado, como os que ocorreram no Brasil em 1964 e no Chile em 1973, assim como a transferência ilegal de poder ao general Charles de Gaulle, na França, em 1958.

Houve realmente uma ruptura institucional na Venezuela? Nos parágrafos que seguem, procuro narrar os principais eventos políticos do ano de 1999 para mostrar que esse foi o caso, com base nas informações fornecidas por duas conhecidas fontes de notícias, o Keesing's Record of World Events e o Latin American Weekly Report. Cumpre lembrar que estas fontes, apesar de escritas em língua inglesa, são muito mais isentas do que os dois grandes jornais venezuelanos (El 
Nacional e El Universal), comprometidos que estão com uma oposição radical a Chávez'.

Durante a campanha presidencial de 1998, Chávez prometera realizar um referendo acerca da convocação de uma assembléia constituinte. Porém, o único mecanismo pelo qual reformas constitucionais poderiam ser feitas, sob a égide da Constituição de 1961, era por meio da aprovação de emendas constitucionais por dois terços do Congresso. Em janeiro de 1999, ainda antes da posse do novo presidente, a Suprema Corte, em resposta a uma consulta de Chávez, determinou que não seria inconstitucional a realização de um referendo a respeito de se uma assembléia constituinte poderia ser convocada. Líderes parlamentares reclamaram da decisão da Corte. Chávez, antes da sua posse, ameaçou dissolver o Congresso caso este se opusesse a seu plano de convocar uma Assembléia Nacional Constituinte. A própria oposição, porém, reconheceu que a convocação da ANC era um processo político, não jurídico. Donald Ramírez, secretário geral do COPEI afirmou que o processo de convocação da ANC “... não é jurídico, mas político, [de modo que] o jurídico não pode ser um obstáculo à execução de uma reforma radical." (Latin American Weekly Report, 19/01/1999).

Às vésperas da posse, os partidos de oposição não se posicionavam mais contra a ANC, mas, isto sim, a favor de que fosse convocada por meio de uma emenda constitucional aprovada pelo Congresso. Acima de tudo, o que Chávez desejava com a ANC era se livrar do Congresso dominado por AD e COPEI, as agremiações políticas que dominaram a vida política venezuelana desde 1959. A convocação da ANC por meio de um referendo foi ou não constitucional?

A decisão da Suprema Corte foi um ato político feito à margem da Constituição de 1961. Ela, a Corte, vergou-se ao intenso clamor dos que apoiavam Chávez. A decisão foi, do ponto de vista constitucional, no mínimo, tão pouco ortodoxa quanto aquela do presidente René Coty de passar a chefia do governo a de Gaulle, em 1958.

O primeiro ato de Chávez como presidente foi assinar um decreto convocando um referendo a respeito da eleição da ANC. O referendo não se cingiria apenas a um sim ou não a propósito da ANC, mas também se manifestaria a respeito da extensão e dos termos da missão da ANC. Chávez emitiu também um ultimato ao Congresso, estabelecendo o prazo de metade de fevereiro para que o Congresso fizesse também a sua própria convocação de referendo, algo nunca antes visto no período 1959-1998.

No final de fevereiro, Chávez enviou ao Congresso um projeto de lei habilitante que Ihe daria poderes de emergência para governar por decreto em questões administrativas, monetárias, fiscais e setoriais. O Congresso optou por

\footnotetext{
${ }^{7}$ Os parágrafos que seguem abaixo reproduzem, quase que verbatim, o texto de Amorim Neto (2002).
} 
emendar o projeto, coisa que Chávez abertamente rejeitou. Além disso, o presidente ordenou que seus ministros não atendessem às convocações feitas a eles pelo Congresso para que lá fossem explicar as medidas exigidas pelo Executivo. Ao fim e ao cabo, no meio de abril de 1999, o projeto de Chávez foi inteiramente aprovado após o presidente instar partidários seus a cercar e pressionar o Congresso. Aqui não há dúvida de que se tratou de uma violação irrefutável das regras do jogo da democracia, pois não consta que, em nenhum regime digno deste nome, projetos do Executivo sejam aprovados com base em cercos ao Poder Legislativo ordenados pelo presidente da República.

Ainda em abril, Chávez afirmou que faltava ao Congresso e à Suprema Corte legitimidade. Ao que esta última respondeu com uma nota exigindo que o chefe do Executivo cessasse suas atitudes desrespeitosas e hostis (Latin American Weekly Report, 20/04/1999). No dia 25 de abril, a pequena fatia do eleitorado que foi às urnas (apenas 37,6\%) deu uma ampla vitória às propostas de Chávez $(87,8 \%$ responderam sim à pergunta $1 ; 81,7 \%$ responderam sim à pergunta 2 ).

Em maio, inicia-se o processo, por assim dizer, informal de dissolução do Congresso eleito em 1998. Quarenta e dois dos 103 deputados e senadores do Pólo Patriótico, nome da aliança dos partidários de Chávez, renunciaram às suas cadeiras parlamentares para concorrer às eleições para a ANC. Treze dos seus suplentes também renunciaram. Com a renúncia dos chavistas, aumentou o controle que a oposição tinha sobre o Congresso, ao preço, porém, de ver diminuída a sua legitimidade. A resposta do Congresso à ação dos chavistas veio com a nomeação de Rafael Pérez Perdomo para o cargo de procurador geral da República. Perdomo havia sido o advogado de defesa de Carlos Andrés Pérez, presidente contra o qual Chávez ensaiou o golpe de estado em 1992 (Latin American Weekly Report, 08/06/1999).

Em junho, Chávez entrou em conflito com o Conselho Nacional Eleitoral (CNE) e, novamente, com o Congresso. O CNE acusou formalmente o presidente de estar mais interferindo do que promovendo a eleição para a ANC ao apoiar abertamente candidatos do governo, favorecê-los com o uso de transporte público e atacar os candidatos da oposição com freqüentes ofensas pessoais, tais como "corruptos" e "ladrões". Chávez respondeu ao CNE com a afirmação de que "Nós não estamos debatendo entre dois caminhos: não há uma terceira via. Vejo isto em preto e branco. Estamos vivendo em tempos apocalípticos na Venezuela e não há espaço para sermos brandos, para tentar estar bem com Deus e o Diabo" (Latin American Weekly Report, 29/06/1999).

Com o Congresso, o conflito se deu em torno da maior lista de promoções militares já feita por um presidente, 262 ao todo, com 52 promoções para o posto de general. A comissão de defesa do Senado, de maioria oposicionista, afirmou que não fazia sentido promover tantos oficiais, uma vez que não havia postos suficientes 
e que recusaria a promoção de 35 oficiais cujas idades já haviam ultrapassado o período de elegibilidade estabelecido pelo código militar. Ao que Chávez respondeu com a afirmação de que os senadores não tinham autoridade moral para agir de tal maneira (Latin American Weekly Report, 29/06/1999) e que pediria à ANC para dissolver o Congresso. A promoção dos 35 militares foi efetivada por Chávez a despeito da decisão do Congresso. Aqui, mais uma vez, um caso de desrespeito aberto à Constituição.

Nas eleições para a ANC, em julho, o Pólo Patriótico obteve nada menos que 122 das 131 cadeiras em disputa. No dia 19 de agosto, a ANC aprovou um decreto criando uma comissão de emergência judicial encarregada de fazer uma reforma radical do Poder Judiciário. Uma pequena maioria da Suprema Corte votou por cooperar com a comissão. A presidente da Corte, Cecília Sosa Gómez, optou por renunciar.

No final de agosto, a ANC declarou o estado de "emergência legislativa", sob o qual estariam suspensas todas as sessões do Congresso e se estabeleceria uma comissão de investigação. Dos dias mais tarde, houve sérios conflitos de rua, no centro de Caracas, entre os partidários de Chávez e os da oposição (Keesing's Record of World's Events, vol. 45, Agosto de 1999). Essa crise foi mais um marco no luta entre o Congresso, dominado pelos velhos partidos, e a ANC, sob o comando das forças chavistas.

No dia 5 de setembro, alcançou-se um acordo entre a ANC e o Congresso, com a mediação da Igreja Católica, que garantiria o pleno funcionamento do Poder Legislativo até a promulgação da nova Constituição, pondo fim ao conflito iniciado no final de agosto com o decreto de emergência legislativa.

No começo de novembro, todavia, revelou-se o quão vazio era o acordo de coexistência. Quando a comissão de finanças do Congresso fez retornar ao Executivo o projeto de orçamento para o ano seguinte alegando uma série de falhas que o tornavam inviável, o governo imediatamente tirou o Congresso do caminho, remetendo o projeto à ANC. Praticamente, não houve reação ao ato do governo (Latin American Weekly Report, 23/11/1999). A anulação do Congresso nesse episódio foi o dénouement final do processo de ruptura institucional.

Finalmente, a Constituição redigida pela ANC foi ratificada pelo referendo popular celebrado no dia 15 de dezembro de 1999. 71,8\% dos eleitores que foram às urnas, representando apenas $44,4 \%$ do eleitorado nacional, deram sua aprovação ao texto. No dia 20 de dezembro, foi promulgada a nova Constituição. $A$ 4 de janeiro de 2000, o Congresso bicameral, eleito em 1998, foi dissolvido. Tal qual estabelecido pela nova Constituição, a Corte Suprema foi dissolvida e substituída por um Supremo Tribunal de Justiça, cujos membros foram escolhidos pela ANC. No dia 31 de janeiro de 2000, o presidente da ANC, Luis Miquelena, é empossado como presidente da legislatura interina, composta de 21 membros, que 
De João Goulart a Hugo Chavez: a política venezuelana à luz da experiência brasileira

exerceria as funções de Poder Legislativo até as eleições gerais inicialmente marcadas para 28 de maio de 2000, nas quais se elegeria uma legislatura unicameral.

Ao fim de julho, foi finalmente realizada a chamada mega-eleição, na qual estavam em disputa a presidência, as 165 cadeiras da Assembléia Nacional e os 23 governos estaduais. Chávez obteve nada menos do que $59,7 \%$ dos votos, a segunda mais ampla maioria alcançada por um candidato nas 11 eleições presidenciais havidas na história do país, atrás apenas dos 74,4\% de votos dados a Rómulo Gallegos, em 1947. Os partidos que endossaram a candidatura de Chávez (Movimiento Va República, MAS, Pátria Para Todos e o Partido Comunista), ficaram com 99 cadeiras parlamentares $(60,0 \%)$. A AD foi reduzida a uma bancada de 30 deputados $(18,2 \%)$ e o COPEI, a 7 (4,2\%). Encerrava-se de forma patética a IV República. Do ponto de vista estritamente constitucional, começava a Va República.

Independentemente do juízo de valor que se tenha a respeito dos propósitos e métodos de Chávez, parece inegável que houve uma ruptura institucional na Venezuela, em 1999. Não é outra a avaliação de Allan R. Brewer-Carías, quiçá o mais prestigioso jurista venezuelano. Em suas palavras,

“... paralelamente à elaboração da nova Constituição, a Assembléia adotou uma série de decisões contidas em Decretos, mediante os quais baixou uma série de atos constituintes, que contrariavam abertamente ao que dispunha a Constituição de 1961, que ainda estava vigente, e aos quais, no entanto, a posteriori, o máximo órgão judicial do país outorgou caráter, natureza e estatuto constitucional. ... Tais atos foram ditados pela Assembléia Nacional Constituinte, como se disse, à margem da ordem constitucional estabelecida na Constituição de 1961, e que foi impunemente desconhecida. A emissão destes atos constituintes desconhecendo a ordem constitucional constituiu um golpe de estado perpetrado pela Assembléia Nacional Constituinte ..." (2002, p.194).

\section{A Crise de Paralisia Decisória}

O que leva à ruptura institucional de um regime democrático? Ou, inversamente, o que faz uma democracia ser estável? Este é certamente um dos temas mais relevantes da ciência política nas últimas quatro ou cinco décadas. Toneladas de tinta ou de toner foram gastas tentando se dar uma resposta à questão. Várias teorias se propuseram a explicar o colapso ou estabilidade da democracia. Mais recentemente, Przeworski, Alvarez, Cheibub e Limongi (2000) realizaram o mais sistemático e abrangente esforço para testar quantitativamente todas as principais hipóteses explicativas da estabilidade dos regimes democráticos, analisando dados de 141 países no período 1950-1990.

Seus principais achados são os seguintes: (1) as democracias têm uma maior probabilidade de sobreviver nos países que já são desenvolvidos; (2) a 
democracia é mais estável em sociedades com melhor distribuição de renda; (3) a heterogeneidade social ou etno-linguística torna qualquer regime, democrático ou autoritário, mais instável; (4) nem o protestantismo nem o islamismo tem algum efeito sobre a durabilidade da democracia; porém, os regimes democráticos têm maiores chances de sobreviver em países nos quais há mais católicos (um resultado surpreendente em vista do consenso teórico existente quanto à pouca afinidade do catolicismo com a democracia); (5) o legado colonial tem um efeito pequeno sobre a estabilidade democrática; (6) a história política dos regimes, seu passado de instabilidade, tem um importante papel nas chances de sobrevivência da democracia; (7) o clima político internacional tem um impacto significativo sobre a estabilidade das democracias, isto é, quanto maior o número de países democráticos no mundo, menor a probabilidade de colapso democrático; e (8) a democracia é menos estável sob o presidencialismo do que sob o parlamentarismo (Przeworski, Alvarez, Cheibub \& Limongi 2000, p.106-136).

Cabe lembrar a maneira pela qual os quatro autores (doravante, PACL) operacionalizaram a variável dependente de seus testes econométricos: se um país era ou não democrático ao final de cada ano no período 1950-1990. Ou seja, PACL se valeram de um critério dicotômico, opondo democracia a autoritarismo, calcado em uma definição schumpeteriana do primeiro regime. Todavia, o conceito aqui adotado de ruptura institucional é, como já mencionado, mais amplo. Um golpe militar que leva à derrubada de um regime democrático é uma ruptura institucional. Porém, uma transferência ilegal do poder, como na França em 1958, ou uma reforma constitucional por meios ilegais, como a feita na Venezuela em 1999, também constitui um caso de ruptura institucional. Seria interessante refazer os testes de PACL operacionalizando-se a variável dependente a partir da noção de ruptura institucional. Um exemplo de como tal noção poderia levar a resultados diferentes daqueles encontrados por PACL é que estes classificaram a França como democrática ao final de 1958 (2000, p.67), favorecendo as hipóteses que afirmam ser a democracia mais estável em países desenvolvidos, com melhor distribuição de renda e sob regimes parlamentaristas.

Infelizmente, ainda não há informação disponível para que se refaçam os testes de PACL a partir da noção de ruptura institucional. Porém, temos a própria teoria desenvolvida por WGS. Segundo este autor, rupturas institucionais em regimes democráticos são conseqüências de crises de paralisia decisória. A paralisia decisória, por sua vez, abre caminho para que alguns grupos procurem romper o impasse existente por meios violentos e pela mudança ilegal das regras do jogo. A questão que se coloca, então, é: como se chega a uma situação de paralisia decisória?

A paralisia decisória decorre de processos simultâneos de dispersão de preferências, intensificação das mesmas e fragmentação dos recursos políticos, 
situação que estimula a formação de coalizões de veto ad hoc, mas que dificulta enormemente a formação de maiorias governativas estáveis. Chega-se, assim, a uma posição de equilíbrio político, a partir da qual o sistema político passa a ser caracterizado pelo impasse permanente (Santos, 1986, p.23-36). Tradução política: a paralisia decisória é fruto do efeito conjugado do aumento de partidos, à esquerda e à direita, em oposição ao governo; da radicalização das suas posições ideológicas e da diminuição do seu tamanho legislativo e do concomitante aumento do número de partidos existentes.

Sob as circunstâncias acima descritas, a cooperação se torna mais difícil porque, com a diminuição do tamanho dos partidos, mais partidos são necessários para se formar uma maioria legislativa e, simultaneamente, os partidos têm menos incentivos para cooperar por conta da radicalização de posições. Como a proliferação de partidos de oposição vem, em geral, de mãos dadas com o aumento do número de partidos, pode-se amalgamar os dois processos sob a rubrica de fragmentação. A intensificação de preferências é, no caso, sinônimo de radicalização ideológica. Em suma, segundo WGS, a paralisia decisória é produto de um processo de fragmentação cum radicalização.

O ganho analítico que se tem com a teoria desenvolvida por WGS é a identificação clara das condições sob as quais se dá um processo de paralisia decisória, permitindo, assim, que se façam predições precisas acerca de quando se deve observar uma ruptura institucional. Ressalte-se que nenhuma das teorias testadas por PACL especifica as condições particulares sob as quais um regime democrático deve entrar em colapso, sendo, portanto, menos úteis para os nossos propósitos.

WGS encontrou fortes evidências de paralisia decisória no Brasil, em 1963, isto é, às vésperas do golpe: a taxa de aprovação de projetos de lei caiu para 0,07 neste ano, enquanto a mesma taxa havia atingido os valores de 0,13,0,13, 0,15 e 0,14, em 1959, 1960, 1961 e 1962, respectivamente.

Outra evidência de paralisia decisória é a diminuição da estabilidade governamental tal qual medida pela taxa de rotatividade dos ministros em seus cargos. A instabilidade governamental aponta, no seu extremo lógico, para a ausência de governo. Assim quanto mais instável a permanência dos ministros em seus postos, menos decisões tomam ${ }^{8}$. Sob a presidência de Dutra, a taxa de estabilidade ministerial foi de 0,36; sob Vargas, 0,32; sob Kubitschek, 0,38; e sob João Goulart, 0,13 (Santos, 1986, p.121).

\footnotetext{
${ }^{8}$ A medida de estabilidade ministerial desenvolvida por WGS (1986, p.121) é a média de permanência dos ministros em seus cargos dividida pela duração constitucionalmente estabelecida do governo.
} 
No que concerne à fragmentação, na legislatura de 1946-1951, o número efetivo de partidos foi de 2,7; na legislatura de 1951-1955, 4,1; na de 1955-1959, 4,6; na de 1959-1963, 4,5; e na legislatura de 1963-1964, 4,6. Ou seja, a fragmentação estava no seu nível máximo no ano que antecedeu ao golpe de $1964^{9}$.

Por último, WGS exibe dados que mostram que, à medida que o Poder Legislativo se fragmentava, mais cadeiras iam para os partidos de direita e esquerda e menos para os partidos de centro-esquerda e centro-direita, configurando uma situação de crescente polarização ideológica (Santos 1986, p.76. 77).

Terá havido uma crise de paralisia decisória antes da chegada de Chávez ao poder semelhante à que ocorreu sob o governo de João Goulart?

A Tabela 3 mostra que, para o período 1994-1999, nunca foi tão baixo o percentual total de projetos de lei aprovados pela Câmara de Deputados $(34,8 \%$ ) e que este percentual vinha declinando consistentemente desde o período 1984 . 1989. Também nunca foi tão baixo o percentual de aprovação de projetos de lei de autoria do Executivo como no quinquênio 1994-1999 (37,8\%). Se não houve paralisia decisória completa no período que precedeu a Chávez, é inegável que a tendência era nesta direção.

Com relação à estabilidade ministerial, a Tabela 4, porém, indica que 0 período 1994-1999 não foi o pior. A estabilidade atingiu o seu nível mais baixo na presidência anterior, de Carlos Andrés Pérez $(0,27)$, presidência que está na origem da crise que levou de roldão o regime de 1958.

No que concerne à fragmentação legislativa, a segunda seção do texto já revelou que a partir de 1989 começou a haver inequívoco aumento da fragmentação. O número efetivo de partidos da legislatura vigente entre 1994 e 1999, 4,5, foi o segundo maior desde 1959.

Por último, no tocante à polarização ideológica, optou-se por medi-la como o percentual de votos obtidos pelos partidos de esquerda, direita, personalistas e outros fora da tradicional clivagem esquerda-direita, tal qual classificados por Coppedge (1997). Segundo essa medida, como mostra a Tabela 5, nunca foi tão alta a polarização como em 1994-1999.

\footnotetext{
${ }^{9}$ WGS, em Anatomia da Crise, não usa o número efetivo de partidos para mediar a fragmentação. Porém, o indicador por ele adotado, o de fracionalização, desenvolvido por Douglas Rae, pode ser facilmente transformado no número efetivo de partidos.
} 
TABELA 3

Produção Legislativa na Venezuela por Período Presidencial-Legislativo (1959-1999)

\begin{tabular}{|c|c|c|c|c|c|c|c|}
\hline Período & 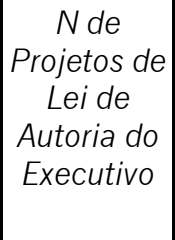 & $\begin{array}{l}N \text { de } \\
\text { Projetos de } \\
\text { Lei de } \\
\text { Autoria do } \\
\text { Executivo } \\
\text { Aprovados }\end{array}$ & $\begin{array}{c}\% \text { de } \\
\text { Projetos de } \\
\text { Lei de } \\
\text { Autoria do } \\
\text { Executivo } \\
\text { Aprovados }\end{array}$ & $\begin{array}{c}N \text { de } \\
\text { Projetos } \\
\text { de Lei de } \\
\text { Autoria da } \\
\text { Câmara }\end{array}$ & $\begin{array}{c}N \text { de } \\
\text { Projetos de } \\
\text { Lei de } \\
\text { Autoria da } \\
\text { Câmara } \\
\text { Aprovados }\end{array}$ & $\begin{array}{c}\text { \% de Projetos } \\
\text { de Lei de } \\
\text { Autoria da } \\
\text { Câmara } \\
\text { Aprovados }\end{array}$ & $\begin{array}{c}\text { \% Total de } \\
\text { Projetos de } \\
\text { Lei } \\
\text { Aprovados }\end{array}$ \\
\hline $\begin{array}{l}1959 . \\
1964\end{array}$ & 53 & 46 & 86,8 & 24 & 10 & 41,7 & 72,7 \\
\hline $\begin{array}{l}1964 . \\
1969\end{array}$ & 64 & 36 & 56,3 & 28 & 10 & 35,7 & 50,0 \\
\hline $\begin{array}{l}1969 . \\
1974\end{array}$ & 83 & 48 & 57,8 & 48 & 23 & 47,9 & 54,2 \\
\hline $\begin{array}{l}1974- \\
1979\end{array}$ & 48 & 32 & 66,7 & 24 & 5 & 20,8 & 51,4 \\
\hline $\begin{array}{l}1979 . \\
1984\end{array}$ & 64 & 32 & 50,0 & 41 & 15 & 36,6 & 44,8 \\
\hline $\begin{array}{l}1984- \\
1989\end{array}$ & 76 & 68 & 89,5 & 51 & 17 & 33,3 & 66,9 \\
\hline $\begin{array}{l}1989 . \\
1994\end{array}$ & 90 & 67 & 74,4 & 77 & 21 & 27,3 & 52,7 \\
\hline $\begin{array}{l}1994- \\
1999 \\
\end{array}$ & 45 & 17 & 37,8 & 106 & 34 & 32,1 & 33,8 \\
\hline
\end{tabular}

Fontes: Venezuela - Camara de Diputados (s/d) para o período 1959-1989 e dados fornecidos por Brian Crisp para o período 1989-1999.

\section{TABELA 4}

Estabilidade Ministerial na Venezuela (1959-1999)

\begin{tabular}{|c|c|c|c|c|c|c|c|}
\hline $1959-$ & $1964-$ & $1969-$ & $1974-$ & $1979-$ & $1984-$ & $1989-$ & $1994-$ \\
1964 & 1969 & 1974 & 1979 & 1984 & 1989 & 1994 & 1999 \\
\hline 0,39 & 0,36 & 0,48 & 0,44 & 0,5 & 0,45 & 0,27 & 0,45 \\
\hline
\end{tabular}

Fontes: Keesing's Record of World Events e Olmos (s/d). 
TABELA 5

$\%$ de Votos Obtido por Partidos Extremistas, Personalistas e Outsiders na Venezuela por Período Presidencial-Legislativo (1959-1999)

\begin{tabular}{|c|c|c|c|c|c|c|c|}
\hline $\begin{array}{c}1959 \cdot \\
1964\end{array}$ & $1964 \cdot$ & $1969 \cdot$ & $1974 \cdot$ & $1979 \cdot$ & $1984 \cdot$ & $1989 \cdot$ & $1994 \cdot$ \\
1969 & 1974 & 1979 & 1984 & 1989 & 1994 & 1999 \\
\hline 6,8 & 1,6 & 15,8 & 13,8 & 17,0 & 18,8 & 17,6 & 23,3 \\
\hline
\end{tabular}

Fontes: Landman (1995), Coppedge (1997) e Venenzuela - Consejo Supremo Electoral (1987; 1990).

A operacionalização empírica mais adequada de um processo de fragmentação cum radicalização requer, contudo, que se multipliquem os dois termos que o compõem. Ou seja, não é a obtenção de um valor alto tanto para fragmentação com para a radicalização que conduz a uma situação de paralisia decisória, mas, isto sim, a obtenção de um valor alto decorrente da interação dos dois termos. A Tabela 6 abaixo exibe o produto da fragmentação com a radicalização para cada período presidencial-legislativo. O período 1994-1999 é, de longe, aquele que atinge o valor mais alto, 104,9. É interessante notar que, no qüinqüênio 1969-1974, coincidentemente também sob a presidência de Rafael Caldera, o produto entre fragmentação e a polarização é o segundo mais alto. Porém, a taxa de produção legislativa deste mesmo período não é a segunda mais baixa. Aqui se verificam claramente os efeitos positivos do Pacto de Punto Fijo, que, ao comprometer os partidos ex ante com uma política de cooperação mútua, permitiu compensar o potencial de paralisia decisória do crescimento do valor do produto da fragmentação cum radicalização.

TABELA 6

Produto entre Fragmentação Legislativa e Radicalização Ideológica na Venezuela por Período Presidencial-Legislativo (1959-1999)

\begin{tabular}{|c|c|c|c|c|c|c|c|}
\hline 1959. & $1964 \cdot$ & $1969 \cdot$ & $1974 \cdot$ & $1979 \cdot$ & $1984 \cdot$ & 1989. & $1994 \cdot$ \\
1964 & 1969 & 1974 & 1979 & 1984 & 1989 & 1994 & 1999 \\
\hline 17,7 & 6,9 & 77,4 & 37,3 & 44,2 & 45,1 & 49,3 & 104,9 \\
\hline
\end{tabular}

Fontes: Tabelas 1 e 5.

Em suma, os dados revelam algumas fortes semelhanças entre as circunstâncias que presidiram o governo de João Goulart, tal qual representadas por WGS, e o segundo governo de Rafael Caldera, com ambos os casos abrindo caminho para um processo de ruptura institucional. Ainda que a ruptura institucional não tenha se dado exatamente no governo de Caldera, esta solução já se insinuara no começo do seu mandato. Logo após assumir a presidência em 1994, Caldera ameaçou dissolver o Congresso e convocar uma assembléia constituinte caso AD e COPEI ficassem no seu caminho (Crisp, 2000, p.38). O que permitiu um mínimo de governabilidade a Caldera foi, após as ameaças que fez, ter 
conseguido do Congresso delegação para governar por decreto em algumas áreas de política econômica. Neste sentido, cumpre ressaltar de que muito do que Chávez fez em 1999 foi em antecipação ao que poderia ocorrer caso o processo político continuasse a ser conduzido sob as antigas regras do jogo político. A legislatura eleita em 1998, além de mais fragmentada do que a anterior, também se encontrava muito mais polarizada por conta do conflito aberto entre chavistas, que estavam em minoria, e a dupla AD-COPEI. No primeiro momento em que AD e COPEI tentaram bloquear as iniciativas de Chávez, este imediatamente recorreu a ameaças de dissolução do Congresso e à violência política.

\section{Discussão}

Obviamente, existem outras interpretações possíveis a respeito do colapso da IVa República. Cabe agora confrontá-las com a oferecida acima.

Para Kornblith (1998, p.161-182) e Rey (1991), a crise do antigo sistema político venezuelano é fruto das transformações havidas no que chamam de sistema populista de conciliação de elites, cujos alicerces eram a renda petrolífera, as altas expectativas de melhoria das condições sociais geradas pelo boom do petróleo da década de 70 e a representatividade das organizações políticas. Os três alicerces se deterioraram conjunta e seriamente a partir da década de 80 , chegando a uma situação limite na década seguinte.

Já Crisp (1998a) nos oferece uma visão mais institucionalista. Segundo o autor, a instabilidade política havida na Venezuela nos anos 90 resultou dos efeitos combinados de três características institucionais: (1) a fraqueza do Congresso como instituição; (2) a centralização do poder no Executivo; e (3) e o reduzido número de grupos consultados no processo decisório. Juntas, estas três características contribuíram para o declínio da legitimidade democrática da IV República ao impedir que alguns setores da sociedade civil participassem do tomada de decisões e ao perpetuar um modelo econômico (centrado na renda petrolífera) que deixara, há muito tempo, de ser produtivo ${ }^{10}$.

As interpretações de Crisp, Kornblith e Rey são convergentes no sentido de enfatizar a incapacidade do antigo sistema político venezuelano de representar ou incorporar eficientemente vários atores sociais. Ou seja, a partidocracia de AD e COPEl transformou-se em oligarquia, justamente em um contexto de crise

\footnotetext{
${ }^{10}$ Com relação aos militares, é óbvio que, ao longo das décadas de 80 e 90, enfraqueceu-se o controle civil sobre a organização castrense. Porém, a grande questão com relação aos militares venezuelanos não é por que passaram a dar golpes, mas, como bem coloca Trinkunas (2002), por que estes fracassaram. De acordo com o analista, a fragmentação do corpo de oficiais promovida pelas instituições civil-militares da IV República é que fizeram fracassar os golpes de 1992 (assim como o de 2002, poder-se-ia dizer) e permitiram que a administração de Caldera retomasse o controle sobre os militares em 19941999.
} 
econômica, levando inicialmente à rejeição da ordem política pela grande maioria de excluídos e, em última instância, ao seu colapso.

Conquanto bastante plausíveis, os argumentos dados pelos três autores não identificam as condições específicas que conduzem à violência política e à ruptura da ordem legal. Afinal de contas, os fatores explicativos por eles listados estavam em ação há quase duas décadas, mas a ruptura institucional só ocorreu em 1999. Neste sentido, a aplicação das hipóteses de WGS à Venezuela nos ajuda a melhor compreender o que aconteceu no país nos últimos anos da década passada ao permitir que se estabeleçam os nexos causais entre os fatores considerados relevantes. Ou seja, a falta de representatividade dos grandes partidos e a sua incapacidade de incorporar novos atores estão intimamente ligados à crescente fragmentação do sistema partidário. Porém, a fragmentação por si só não leva a crises de paralisia decisória. É preciso que venha acoplada a um processo de radicalização ideológica. Esta foi desencadeada pela crise econômica que se abateu sobre a economia petroleira venezuelana na década de 90. A combinação de fragmentação com radicalização, esta sim, ocasionou o imobilismo decisório que caracterizou a segunda administração de Rafael Caldera em 1994-1999, abrindo caminho para que o grave impasse político em que se encontrava o país fosse resolvido pelo recurso à violência política e à ruptura institucional, de forma muito parecida ao que se deu no Brasil em meados da década de 60.

\section{Conclusão}

As hipóteses de WGS sobre as condições políticas que levaram ao golpe de 1964 no Brasil revelaram-se bastante úteis para analisar o colapso da IVa República venezuelana em 1999. Porém, uma confirmação cabal destas hipóteses requer um sofisticado exercício econométrico tal qual o realizado por PACL. Isto é, é preciso que, em primeiro lugar, se estipulem critérios de identificação empírica de eventos de ruptura institucional e que se apliquem tais critérios a uma ampla amostra de países ao longo de um razoável período de tempo. Em segundo lugar, deve-se obter dados para que se calculem a fragmentação legislativa e a radicalização ideológica para cada país, em cada unidade de tempo. O mais difícil desta tarefa é conseguir informações sobre a radicalização. Por último, o termo interativo que compreende a interação da fragmentação com a radicalização deve exibir alta significância estatística na presença de outras variáveis independentes consideradas pertinentes para a explicação de rupturas institucionais, tais como o sistema de governo, a heterogeneidade social, o nível de desenvolvimento sócio-econômico e crises econômicas.

Enquanto não se realiza tal teste, estudos de caso constituem um bom método de pesquisa. O Brasil, em 1964, o Chile, em 1973, a França, em 1958, e a 
Venezuela, em 1999, são exemplos que parecem corroborar as hipóteses de WGS. Porém, cabe lembrar que WGS desenvolveu seu trabalho na década de 70, ainda sob forte influência da revolução behaviorista e distante da revolução neoinstitucionalista que varreria a ciência política na década seguinte. 0 behaviorismo explica os resultados (outcomes) como função da distribuição de preferências e recursos, enquanto que o neo-institucionalismo vê aqueles como função da interação de incentivos institucionais e preferências. Reconciliar, teórica e empiricamente, as duas abordagens na análise da estabilidade democrática e de rupturas institucionais, eis uma agenda de pesquisa que ainda está por ser executada.

\section{BIBLIOGRAFIA}

AMORIM NETO, Octavio. (2002) Manual do Perfeito Aventureiro Latino-Americano: Hugo Chávez. Revista Inteligência, 18:42-46.

(1998) Of Presidents, Parties, and Ministers: Cabinet Formation and Legislative Decision-Making Under Separation of Powers. San Diego, Tese de Doutorado, Universidade da Califórnia.

. (1999) O Amargo Despertar Venezuelano. Revista Inteligência, 6:78-87.

BREWER-CARÍAS, Allan R. (2002) Golpe de Estado y Proceso Constituyente en Venezuela. México, Universidad Nacional Autónoma de México.

COPPEDGE, Michael. (1994) Strong Parties and Lame Ducks: Presidential Partyarchy and Factionalism in Venezuela. Stanford, Stanford University Press.

COPPEDGE, Michael. (1997) A Classification of Latin American Political Parties. Kellog Institute Working Paper No. 244.

CAREY, John M. \& SHUGART Mathew S. (1995) Incentives to Cultivate a Personal Vote: a Rank Ordering of Electoral Formulas. Electoral Studies, 14:417-439.

COMBELLAS LARES, Ricardo. (1985) COPEl: Ideologia y Liderazgo. Caracas, Editorial Ariel.

CRISP, Brian F. (1998a) Institutional Design and Compromised Legitimacy. In: CANACHE, Damarys \& Kulisheck Michael R. Reinventing Legitimacy: Democracy and Political Change in Venezuela, (orgs.). Westport: Greenwoood Press.

(1998b) Variation in Legislative Entrepreneurship in Venezuela. Trabalho apresentado no encontro da Latin American Studies Association, Chicago, setembro 24-26.

(2000) Democratic Institutional Design: The Powers and Incentives of Venezuelan Politicians and Interest Groups. Stanford, Stanford University Press.

KARL, Terry Lynn. (1991) Petroleum and Political Pacts: The Transition to Democracy in Venezuela. Latin American Research Review, 23:61-89.

KORNBLITH, Miriam. (1996) Crisis y Transformación del Sistema Político Venezolano: Nuevas y Viejas Reglas de Juego. In: ALVAREZ, A. (org.) Crisis y Transformación del Sistema Político Venezolan. Caracas, Instituto de Estudios Políticos, Universidad Central de Venezuela.

KORNBLITH, Miriam. (1998) Venezuela en los 90: Las Crisis de la Democracia. Caracas: Ediciones IESA. 
KORNBLITH, Miriam \& LEVINE, Daniel H.. (1995) Venezuela: The Life and Times of the Party System. In: MAINWARING, Scott \& SCULLY, Timothy R. (orgs.) Building Democratic Institutions: Party Systems in Latin America. Stanford University Press.

KULICHECK, Michael. (1997) Electoral Laws and Politicians: The Behavioral Effects of Electoral Reform in Venezuela. Trabalho apresentado no encontro anual da American Political Science Association.

LANDMAN, Todd. (1995) 'El Chiripero' Wins: The Venezuelan Elections of 1993. Electoral Studies, 14:100-104.

LEVINE, Daniel H. (1973) Conflict and Political Change in Venezuela. Princeton, Princeton University Press.

LIJPHART, Arend. (1976) Democracy in Plural Societies: A Comparative Exploration. New Haven, Yale University Press.

LIJPHART, Arend. (1999) Patterns of Democracy: Government Forms and Performance in Thirty-Six. New Haven, Yale University Press.

MAINWARING, Scott. (1991) Politicians, Parties, and Electoral Systems: Brazil in Comparative Perspective. Comparative Politics, 24:21-43.

MAINWARING, Scott \& SCULLY, Timothy R. (1995) Introduction: Party Systems in Latin America. In: MAINWARING, Scott \& SCULLY, Timothy R. (orgs.) Building Democratic Institutions: Party Systems in Latin America. Stanford University Press.

NAVARRO, Juan Carlos. (1988) Pactos Políticos y Estilos Decisionales: Tres Teorias Frente al Pacto de Punto Fijo y al Pacto Social. Politeia, 12:193-220.

OLMOS, Helena. (s/d) Ministros de la Democracia. Caracas, Instituto Autonomo Biblioteca Nacional - Colección de Publicaciones Oficiales.

PRZEWORSKI, Adam, ALVAREZ, Michael, CHEIBUB, José Antonio \& LIMONGI, Fernando. (2000). Democracy and Development: Political Institutions and Material Well-Being in the World, 1950-1990. Cambridge, Cambridge University Press.

REY, Juan Carlos. (1991) La Democracia Venezolana y la Crisis del Sistema Populista de Conciliación. Revista de Estudios Políticos, 74:533-578.

SANTOS, Wanderley Guilherme dos. (1986). Sessenta Quatro: Anatomia da Crise. São Paulo, Vértice.

SHUGART, Matthew S. (1992) Leaders, Rank and File, and Constituents: Electoral Reform in Colombia and Venezuela. Electoral Studies, 11:21-45.

SHUGART, Matthew S. e John M. Carey. (1992) Presidents and Assemblies: Constitutional Design and Electoral Dynamics. Cambridge, Cambridge University Press.

TRINKUNAS, Harold A. (2002) The Crisis in Venezuelan Civil-Military Relations: From Punto Fijo to the Fifth Republic. Latin American Research Review, 37:41-76.

Venezuela - Camara de Diputados. (s/d) Registro de Matérias, vols. I-III. Mimeo, Caracas: Archivo de Diputados.

Venezuela - Consejo Supremo Electoral. (1987) Los Partidos Políticos Venezolanos y Sus Estadísticas Electorales, 1946-1984, 2 vols. Caracas, Consejo Supremo Electoral - División de Estadística.

Venezuela - Consejo Supremo Electoral. (1990) Elecciones 1988, 2 vols. Caracas: Consejo Supremo Electoral División de Estadística. 